\title{
Frailty: a new vulnerability indicator in people aging with HIV
}

\author{
Thomas D. Brothers ${ }^{1} \cdot$ Kenneth Rockwood ${ }^{2,3}$ (i)
}

Received: 21 October 2018 / Accepted: 24 November 2018 / Published online: 10 December 2018

(c) European Geriatric Medicine Society 2018

\begin{abstract}
Purpose To review the concept of frailty and its measurement, describe the existing data on frailty in people living with HIV, examine the limits of frailty as a marker of vulnerability in people living with HIV, and explore how frailty measurement could be incorporated into HIV care.

Methods Narrative literature review.

Results Frailty is an emerging marker of vulnerability that is increasingly being assessed among people aging with HIV. Which frailty measurement tool is best for people with HIV has not yet been established, and likely depends on clinical context. Evaluation of vulnerability should take into account social and structural factors. Frailty assessment can be incorporated into clinical care as a part of comprehensive geriatric assessment. Models of HIV-geriatric care are being established. Conclusions As a group, people with HIV are aging and increasingly face multiple interacting age-related medical and social problems. It requires remarkable resilience to age successfully with HIV. The clinical care of people aging with HIV could benefit from a focus on frailty and related social vulnerability to better understand patients' needs and develop appropriate goals and care plans.
\end{abstract}

Keywords HIV · Aging · Frailty · Social vulnerability · Risk environment · Comprehensive geriatric assessment

\section{Introduction}

Modern antiretroviral therapies have transformed the course of human immunodeficiency virus (HIV) disease and the global HIV epidemic. For people who can access and regularly take medication, HIV has become a chronic, manageable condition [1]. People living with HIV who remain on lifelong treatment can now expect life expectancies comparable to people without HIV infection [2]. This is particularly true for those who retain healthy immune function with high CD4 cell counts and suppressed viral load on modern medication regimens [3].

Kenneth Rockwood

kenneth.rockwood@dal.ca

1 Department of Medicine, Dalhousie University, Halifax, NS, Canada

2 Division of Geriatric Medicine, Dalhousie University, 1421-5955 Veterans' Memorial Lane, Halifax, NS B3H 2E1, Canada

3 Centre for Health Care of the Elderly, QEII Health Sciences Centre, Nova Scotia Health Authority, Halifax, NS, Canada
As a consequence of this success, people living with treated HIV are now aging and so increasingly face agerelated health challenges [4-6]. People aging with HIV are consistently found to have high rates of illnesses that are strongly associated with advanced age in general population cohorts, including cardiovascular, kidney, lung, bone, endocrine, and liver diseases [7,8]. Geriatric syndromes such as cognitive impairment, falls, and incontinence are common among people with HIV aged 50 years and older [9]. The prevalence of these conditions may be higher among people living with HIV than among people without HIV of the same age. In longitudinal studies, aging-related declines in gait speed [10] and grip strength [11] appear to be accelerated in people with HIV.

Exactly why people with HIV may experience higher rates of aging-related diseases than people without HIV is attracting ongoing investigation [3]. Many factors contribute to increased risk, including those related to HIV disease and its treatment (e.g., CD4 count and viral load; adverse effects of HIV antiretroviral medications); to aging itself (e.g., chronic inflammation, cellular senescence); and to the social and personal environment [5]. Many of these factors are interacting. For example, more excess life years lost have 
now been attributed to smoking than to HIV infection itself among people living with treated HIV [12], and people with HIV are more likely to smoke if they have experienced poverty or social exclusion [13].

People tend to accumulate more health problems as they age. Even so, different people of the same age experience enormous variability in their overall health status, function, and vulnerability to poor health outcomes. This heterogeneity in the risk of adverse health outcomes among people of the same chronological age is how the statistical sense of "frailty" was first defined [14, 15]. If aging is defined as the time-dependent functional decline that affects most organisms, then conceived in this way, frailty is akin to summarizing biological aging, as opposed to chronological age [5, 15].

Frailty is an emerging framework for understanding and measuring age-related vulnerability among people aging with HIV who experience multiple interacting medical and social problems. Here we review the concept of frailty and its measurement, describe the existing data on frailty in people living with HIV, examine the limits of frailty as a marker of vulnerability in people living with HIV, and explore how frailty measurement could be incorporated into HIV care.

\section{Frailty}

Although most frailty research has focused on older adults, frailty can be measured across the life course [16, 17]. Frailty is strongly associated with advancing age, and older people tend to be frailer than younger people on average. This reflects the accumulation of unrepaired damage across the life course, as more insults are experienced with the passage of time and intrinsic repair mechanisms begin to deteriorate [18]. Whereas the severity of frailty on an average worsens with age, it can also stabilize or even improve over time [19]. The progression (or stability, or improvement) of frailty severity is affected by multiple factors, including differences in the rate of insults people experience from their environment, and differences in intrinsic repair capacity [18]. Protective factors include education, physical activity, and wealth, and some of the socioeconomic gradient in frailty has been explained by life course differences in health behaviors and cardiometabolic risk [20]. Diverse challenging life experiences have been associated with worsening frailty, including childhood hunger [21], childhood physical abuse and interpersonal violence [22] over the life course, and birth in low- and middle-income countries [23].

Frailty is strongly associated with multiple adverse health outcomes, including hospitalization, death, and placement in long-term care [15]. Frailty predisposes people to larger deteriorations in health after a stressor event, and may preclude returning to baseline functional status. Even so, the relationship between a given level of frailty and the risk of an outcome is not uniform. It is interesting that people with the same degree of frailty experience different risks. For example, women consistently tend to be frailer than men of the same age, but are at relatively lower risk of death [15]. Among people with the same degree of frailty, those who are more socially vulnerable experience a much higher risk of death $[24,25]$. Conversely, this varying risk amongst people of the same degree of frailty has also been explained by markers of variable resilience [26].

\section{Measuring frailty}

A patient's severity of frailty is commonly assessed in geriatric medicine as a part of comprehensive geriatric assessment and care planning, but a single best frailty measurement tool has not been identified. Many operational definitions of frailty and associated measurement tools are used in clinical practice [27, 28]. Most frailty measurement tools assess the severity of health deficits that a person has accumulated across multiple health domains over time [29]. This can be done by overall clinical judgment, for example with the Clinical Frailty Scale [30], or by counting the number of health deficits someone has accumulated out of a group of health variables, creating a frailty index $[14,31]$ (often based on a comprehensive geriatric assessment [32]). Some frailty measurement tools are designed to count the accumulation of a few specific health deficits, including the commonly used five-item Fried frailty phenotype [33] and FRAIL scales [34], and the 17-point Edmonton Frail Scale [35]. One frailty scale, the Veterans Ageing Cohort Study (VACS) Index, was specifically developed for and validated among people living with HIV [36]. Some frailty measurement scales have been designed to label people as "frail", "pre-frail", or "robust" or "not frail", while others grade severity of frailty as a continuum [27, 29]. Frailty scales that incorporate more information and grade the severity of frailty may be more cumbersome to use, but tend to be more informative $[27,28]$ and may be automatically calculated when incorporated into electronic medical records [37]. Across different research studies, modifications to frailty measurement tools are common and significantly change their predictive properties [38].

Many frailty measurement scales comprise biological and clinical variables. Others include measurements of function or home care supports, as in a comprehensive geriatric assessment. Fewer frailty scales incorporate markers of social, economic, or structural vulnerability [39]. Frailty scales rarely specifically incorporate issues that may be more common among some people aging with HIV such as substance use, homelessness, food insecurity, or stigma-related social and economic exclusion. One common approach has been to assess the social and structural vulnerability factors 
separately from frailty, and measure the severity of vulnerability in a "social vulnerability index" [24]; this may help to understand the variability in outcomes among people with the same degree of frailty.

The best frailty measurement tool in HIV care likely depends on its purpose and clinical context [40]. Some scales that incorporate measures of physical performance, such as gait speed or grip strength, may not be appropriate in those people who are more severely frail or too impaired to complete the task. The best simple screening test to identify those patients who might be frail would surely be different than the best comprehensive frailty measurement based on a comprehensive geriatric assessment. The best frailty measurement tools to use in HIV primary care, HIV specialists clinics, or HIV-geriatric consultation services have not yet been established [41, 42].

\section{Frailty in people aging with HIV}

Frailty has been identified and measured among people aging with HIV, using multiple different measurement tools [5, 9, 40, 43, 44]. Most of this work has been observational, chiefly in cross-sectional studies. One pilot pre-post intervention study among ten people living with HIV showed improvements in some aspects of the frailty phenotype with an exercise gaming intervention [45].

Similar to other age-related health conditions in people living with HIV, the incidence and severity of frailty have been associated with multiple factors related to HIV disease, individuals' intrinsic biology, and social and structural environment [5, 43, 44]. Greater severity of frailty has been associated with increasing age, longer time since HIV diagnosis [46, 47], lower current [48, 49] and nadir [50] CD4 count, lower CD4/CD8 ratio [51], detectable viral load [52], and use of protease inhibitor-containing therapy regimens [46]. Other studies have identified an association between frailty and serum markers of inflammation and testosterone levels [53]. Co-morbid conditions including hepatitis $\mathrm{C}$ virus coinfection [54], diabetes [52], kidney disease [52], chronic obstructive pulmonary disease [55], pain [56], depression [51], obesity, sarcopenia [57], and osteoporosis [58] have also been associated with more severe frailty. Frailty has also been associated with behavioral, social, and structural factors in people aging with HIV, including smoking [49], injection drug use [59], lower education [48], unemployment [46], low income [46], and food insecurity [51].

Depending on the frailty framework that is used, or the question being asked, each of these co-factors or co-morbidities could either be incorporated into a frailty measurement tool or analyzed separately $[59,60]$. Overall, the accumulation of more co-morbid diagnoses, laboratory abnormalities, and social and structural adverse conditions contribute to more severe frailty and also to the lethality of a given level of frailty [5]. The more things that a person has wrong, the frailer and more vulnerable they tend to be. In longitudinal studies among people living with HIV, frailty has predicted multiple adverse outcomes including functional impairment [51], cognitive impairment [61], hospitalization [36, 62], fragility fractures [63], incident multimorbidity [59], cardiovascular mortality [64], post-liver transplant morbidity and mortality [65], and all-cause mortality [48, 49, 59].

Many recent studies have explored the relationship between frailty and cognitive impairment in particular among people aging with HIV. Cognition declines variably with age, and is associated with frailty and the accumulation of health deficits in both the general population and among people living with HIV [61, 66-69]. People living with HIV may suffer the long-term effects of HIV-associated neurocognitive disorder (HAND) as well as age-related cognitive decline and dementia [66]. In several recent studies of people aging with HIV, frailty was positively associated with concurrent cognitive impairment [67-70]. People with HIV and cognitive impairment who are also frail face increased risk of falls, disability, and death compared to those who are not also frail [66]. People with HIV who are frail may face more rapid cognitive decline than those who are not frail [61].

\section{Why might people living with HIV experience a greater burden of frailty?}

Compared to people without HIV, people living with HIV of the same age may experience a greater burden of frailty [71]. People living with HIV, as a group, tend to differ from people without HIV in many ways. Along with the virus and medication experience, and associated immune dysfunction and chronic inflammation, this includes higher rates of social, structural, and biological factors that may increase the rate of health insults, or diminish the body's ability to repair insults, across the life course. These factors which are more common among people aging with HIV include experiences of poverty [72], food insecurity [73], racism and homophobia [74], homelessness [75], smoking [13], and HIV-related stigma, and social isolation. Many people living with HIV experience more than one of these factors simultaneously. In particular, people with HIV are more likely to belong to vulnerable "key populations" identified by UNAIDS, including men who have sex with men, sex workers, transgender people, and people who are incarcerated. These factors may influence vulnerability and the accumulation of deficits across the life course.

Investigating frailty among cohorts of socially and structurally vulnerable populations can be challenging, as at any given time people who are most vulnerable may die and cohorts can 
only follow the survivors (who are inherently healthier). This is one explanation for why health disparities seem to diminish as people reach older ages [76]. The most vulnerable people are also less likely to participate in longitudinal studies.

\section{Frailty and social vulnerability among people aging with HIV}

Different frameworks exist to understand the relationship between frailty (capturing biomedical vulnerability) and actual risk of adverse outcomes. These may be particularly useful to explore in people living with HIV who are at higher risk of social and structural vulnerabilities that might not be captured in traditional frailty measurement scales. People who are frail and people living with HIV may also be more vulnerable to negative outcomes from policy focused on individual health behaviors without providing appropriate social supports or a focus on equity $[24,77]$.

One concept that has been explored in the general population is the relationship between frailty and social vulnerability with the risk of adverse outcomes [24]. This approach conceptualizes social vulnerability analogously to frailty, as an accumulation of social deficits that are more likely to occur with age (but not universally so) and also are affected by both intrinsic and extrinsic factors. The more socially vulnerable a person is, the more likely they are to experience adverse outcomes independent of their level of frailty [25]. A recent paper focused on protective social factors and resiliency (rather than vulnerability) demonstrated construct validity of a "protective factors index" in people with HIV [60].

Socioeconomic status, income, education, social supports, social isolation or exclusion, social cohesion, social capital, and social welfare policies all may have important effects on the risk of adverse outcomes among people who are frail [24]. These represent effects and potential interventions at different levels, from those focused on the individual to those focused on government or society more generally. Analytic frameworks used to investigate these levels of social influence on the health of older adults include "human ecology" and "social ecology" [24].

Social vulnerability may explain some of the relationship between frailty and adverse outcomes in people aging with HIV [78], and is being increasingly explored in this population.

\section{Frailty and the "risk environment" in people aging with HIV}

Approaches from HIV risk and prevention research may also be informative in trying to understand the vulnerability and frailty in people aging with HIV. The concept of "risk environments", as developed by Tim Rhodes, has been advanced to examine the risk of HIV acquisition and drug-related harm among people who inject drugs [77, 79]. It may be helpful in trying to understand the risk of age-related adverse outcomes among people with HIV who are frail.

A risk environment is the space (whether physical, social, economic, or policy) in which multiple factors interact to increase or decrease the chances of a harmful outcome [77].

The risk environment framework invites us to consider risk as more than simply related to intrinsic individual factors and to situate an individual's risk within the social and environmental structures that surrounds them [77].

Micro risk environments can include factors related to perceived social norms, rules, values, the structure of social networks, and the local neighborhood context in which people live [77]. For people with HIV who are frail, this could include the nature of relationships with friends and family, taking into account the social norms leading to discrimination related to HIV status, sexual orientation, or substance use. The physical structure of residential neighborhoods, including walkability or safety, could determine physical activity levels, social engagement, and, therefore, be a mediator in the pathway between frailty and the risk of falls and death.

Macro risk environment may include factors related to policies and laws, systemic discrimination as it plays out in society at large, and social and material inequities [81]. For older adults living with HIV, this could include policies regulating the availability of safe housing for those with low incomes, or the provision of funding for medication or nutritious food supplements. These could affect the risk that someone developed sarcopenia and functional decline. Policies regarding the provision of home care could determine who is hospitalized or is placed in long-term care.

This framework may also be helpful in terms of understanding how to reduce the risk of adverse outcomes among people with HIV who are frail. "Enabling environments" could be established to reduce the risk of adverse outcomes among people who are frail.

To our knowledge, the risk environment framework has not been explored in the context of understanding the risk for aging-related harms in people aging with HIV, although a large body of work relates individual social and environmental factors to adverse health among older adults including related concepts of human ecology and social ecology [24]. This work is needed, and may be of particular relevance to understanding the health needs of people with HIV who are frail. Such an approach could inform designing of clinical and policy interventions to reduce the risks of aging-related harms in this group. 


\section{Incorporation of frailty into HIV care-the utility of frailty assessment}

As more effective and tolerable antiretroviral medications have changed the natural history of HIV disease for people on treatment, clinical indicators of biological vulnerability have also changed. In the era before combination antiretroviral therapy, the HIV clinical focus was often on the prevention and treatment of opportunistic infections. As early antiretroviral therapies helped restore and maintain immune function, troubling metabolic side effects became a focus for HIV clinics. In the new era of HIV care, chronic diseases of aging, including cardiovascular disease, COPD, and chronic kidney disease have become a focus. Identification of frailty and related geriatric syndromes, and incorporation of this information into care planning are now emerging foci in HIV care [80].

Screening for frailty and geriatric syndromes in clinical care involves evaluating multiple domains of function, physical health, cognition, mental health, formal and informal care supports, and more. The focus of care can change from avoiding mortality to maximizing function and quality of life. Decisions to undertake referrals to multiple subspecialists for different disease diagnoses, or plans for appropriateness of specific interventions, can be assessed in the context of a patient's overall health, vulnerability, and goals.

In geriatric medicine, the most robustly studied method for accomplishing this is through comprehensive geriatric assessment (CGA). This usually involves assessing and creating management plans across multiple domains of health and function. This is often done in a multidisciplinary team. Practitioners then incorporate the CGA information and frailty assessment into decision-making and care planning.

As people living with HIV develop more aging-related problems, they are more often referred to subspecialists for individual disease management. There are few HIV-geriatric specific services to place individual chronic disease management in the context of CGA, frailty, and patients' overall goals. In a recent survey of HIV clinics in the UK, only 5 HIV clinics out of 102 had a clinician with specific training or a focus on aging [42]. Further, 23\% of the clinics identified a need for a specific aging-related care service. While $68 \%$ of the clinics supported dedicated guidance for monitoring and assessment among older adults with HIV, $41 \%$ supported dedicated guidance on treatment [42].

The most recent update of the Italian HIV care guidelines includes a section on managing aging and frail patients with HIV, which generally recommends assessments for frailty and comprehensive geriatric assessment
(CGA) [6, 81]. The American Academy of HIV Medicine, the AIDS Community Research Initiative of America (ACRIA), and the American Geriatrics Society 2012 guidelines on managing older adults with HIV also speak generally to the utility of frailty and functional assessment [82]. A number of recent best-practice clinical review papers focus on assessing and managing age-related conditions in older people with HIV, including geriatric syndromes and frailty [83-85]. Important principles raised by this early literature include the importance of CGA in guiding care planning for people with HIV who are frail. Medication review, including potential interactions between multiple antiretroviral drugs and multiple drugs for age-related chronic health problems, may be a particular focus of these care models [4].

The best models for incorporating geriatric medicine principles into subspecialty medicine, including HIV care, have not yet been established but are an area of active investigation [41]. A few specialty geriatric-HIV services have been described. One HIV-aging service operates monthly with a geriatrician and HIV physician present in a joint clinic model [42]. Referral criteria are based on age and need, including multimorbidity and polypharmacy. The clinic offers comprehensive geriatric assessment and full medication review. A second HIV-aging service is a weekly clinic with an HIV physician and a nurse specialist with an interest in aging, without a geriatrician. Another program described in the literature consists of geriatricians providing weekly geriatric consultation within an HIV clinic, and attending discussions at interdisciplinary care rounds [80].

It is likely that different models of care are best based on the local resources, expertise, and identified need. Even within general geriatric medicine the evidence for specific care models incorporating comprehensive geriatric assessment into care planning is mixed, and this is also true for geriatric consultative or specialist services for specific health conditions [86]. This may be in part because the best outcome measures to identify when assessing the complex interventions have still not been established. Often the focus is on global measures of health-related quality of life, while individualized measures like Goal Attainment Scaling (GAS) may be more responsive or appropriate [87].

\section{Conclusion}

Initiatives aimed at meeting the "90-90-90" targets proposed by the WHO (that is $90 \%$ of the people with HIV diagnosed, $90 \%$ of those diagnosed on treatment, and $90 \%$ of those on treatment with a suppressed viral load) will eventually help to end the epidemic, and will also lead to even more people with HIV living to older ages. 
As a group, people with HIV are aging and increasingly face multiple interacting age-related medical and social problems. It requires remarkable resilience to age successfully with HIV. As such, the clinical care of people aging with HIV could benefit from a focus on frailty and related social vulnerability to better understand patients' needs and develop appropriate goals and care plans.

Author contributions We thank Lindsay M. K. Wallace, MSc, for helpful comments on an earlier draft

\section{Compliance with ethical standards}

Conflict of interest T.D.B. is supported by the Ross Stewart Smith Fellowship in Medical Research from the Dalhousie University Faculty of Medicine. K.R. is founder and Chief Scientific Officer of DGI Clinical, which has contracts with several companies for individualized outcome measures and advanced data analytics. Through the Dalhousie Technology Transfer Office, he has asserted copyright of the Clinical Frailty Scale.

Ethical approval This article does not contain any studies with human participants or animals performed by any of the authors.

Informed consent For this type of study formal consent is not required.

\section{References}

1. Deeks SG, Lewin SR, Havlir DV (2013) The end of AIDS: HIV infection as a chronic disease. Lancet 382:1525-1533

2. Teeraananchai S, Kerr SJ, Amin J, Ruxrungtham K, Law MG (2017) Life expectancy of HIV-positive people after starting combination antiretroviral therapy: a meta-analysis. HIV Med 18:256-266

3. Sabin CA, Reiss P (2017) Epidemiology of ageing with HIV: what can we learn from cohorts? AIDS 31:S121

4. Smit M, Brinkman K, Geerlings S, Smit C, Thyagarajan K, van Sighem A et al (2015) Future challenges for clinical care of an ageing population infected with HIV: a modelling study. Lancet Infect Dis 15:810-818

5. Brothers TD, Rockwood K (2014) Biologic aging, frailty, and agerelated disease in chronic HIV infection. Curr Opin HIV AIDS 9:412-418

6. Guaraldi G, Palella FJJ (2017) Clinical implications of aging with HIV infection: perspectives and the future medical care agenda. AIDS 31:S129

7. Guaraldi G, Orlando G, Zona S, Menozzi M, Carli F, Garlassi E et al (2011) Premature age-related comorbidities among HIVinfected persons compared with the general population. Clin Infect Dis 53:1120-1126

8. Althoff KN, McGinnis KA, Wyatt CM, Freiberg MS, Gilbert C, Oursler KK et al (2015) Comparison of risk and age at diagnosis of myocardial infarction, end-stage renal disease, and non-AIDSdefining cancer in HIV-infected versus uninfected adults. Clin Infect Dis 60:627-638

9. Greene M, Covinsky KE, Valcour V, Miao Y, Madamba J, Lampiris $\mathrm{H}$ et al (2015) Geriatric syndromes in older HIV-infected adults. J Acquir Immune Defic Syndr 69:161-167

10. Schrack JA, Althoff KN, Jacobson LP, Erlandson KM, Jamieson BD, Koletar SL et al (2015) Accelerated longitudinal gait speed decline in HIV-infected older men. JAIDS J Acquir Immune Defic Syndr 70(4):370-376

11. Schrack JA, Jacobson LP, Althoff KN, Erlandson KM, Jamieson BD, Koletar SL et al (2016) Effect of HIV-infection and cumulative viral load on age-related decline in grip strength. AIDS 30:2645-2652

12. Helleberg M, May MT, Ingle SM, Dabis F, Reiss P, Fätkenheuer $\mathrm{G}$ et al (2015) Smoking and life expectancy among HIV-infected individuals on antiretroviral therapy in Europe and North America. AIDS 29:221-229

13. Mdodo R, Frazier EL, Dube SR, Mattson CL, Sutton MY, Brooks JT et al (2015) Cigarette smoking prevalence among adults with HIV compared with the general adult population in the United States: cross-sectional surveys. Ann Intern Med $162: 335$

14. Mitnitski AB, Mogilner AJ, Rockwood K (2001) Accumulation of deficits as a proxy measure of aging. Sci World J 1:323-336

15. Clegg A, Young J, Iliffe S, Rikkert MO, Rockwood K (2013) Frailty in elderly people. Lancet 381:752-762

16. Rockwood K, Blodgett JM, Theou O, Sun MH, Feridooni HA, Mitnitski A et al (2017) A frailty index based on deficit accumulation quantifies mortality risk in humans and in mice. Sci Rep 7:43068

17. Blodgett JM, Theou O, Howlett SE, Rockwood K (2017) A frailty index from common clinical and laboratory tests predicts increased risk of death across the life course. GeroScience 39:447-455

18. Rutenberg AD, Mitnitski AB, Farrell SG, Rockwood K (2018) Unifying aging and frailty through complex dynamical networks. Exp Gerontol 107:126-129

19. Thompson MQ, Theou O, Adams RJ, Tucker GR, Visvanathan R (2018) Frailty state transitions and associated factors in South Australian older adults. Geriatr Gerontol Int. https://doi. org/10.1111/ggi.13522 (Epub ahead of print)

20. Brunner EJ, Shipley MJ, Ahmadi-Abhari S, Valencia Hernandez C, Abell JG, Singh-Manoux A et al (2018) Midlife contributors to socioeconomic differences in frailty during later life: a prospective cohort study. Lancet Public Health 3:e313-e322

21. Abeliansky AL, Strulik H (2018) Hungry children age faster. Econ Hum Biol 29:211-220

22. Dos Santos Gomes C, Pirkle CM, Zunzunegui MV, Guedes DT, De Barbosa JF, Hwang P et al (2018) Frailty and life course violence: the international mobility in aging study. Arch Gerontol Geriatr 76:26-33

23. Brothers TD, Theou O, Rockwood K (2014) Frailty and migration in middle-aged and older Europeans. Arch Gerontol Geriatr 58:63-68

24. Andrew MK, Keefe JM (2014) Social vulnerability from a social ecology perspective: a cohort study of older adults from the National Population Health Survey of Canada. BMC Geriatr $14: 90$

25. Wallace LMK, Theou O, Pena F, Rockwood K, Andrew MK (2015) Social vulnerability as a predictor of mortality and disability: cross-country differences in the survey of health, aging, and retirement in Europe (SHARE). Aging Clin Exp Res 27:365-372

26. Rockwood K, Mitnitski A (2015) Resilience and frailty: further steps, best taken together. Eur Geriatr Med 6:405-407

27. Theou O, Brothers TD, Mitnitski A, Rockwood K (2013) Operationalization of frailty using eight commonly used scales and comparison of their ability to predict all-cause mortality. J Am Geriatr Soc 61:1537-1551

28. Dent E, Kowal P, Hoogendijk EO (2016) Frailty measurement in research and clinical practice: a review. Eur J Intern Med 31:3-10

29. Theou O, Brothers TD, Peña FG, Mitnitski A, Rockwood K (2014) Identifying common characteristics of frailty across seven scales. J Am Geriatr Soc 62:901-906 
30. Rockwood K, Song X, MacKnight C, Bergman H, Hogan DB, McDowell I et al (2005) A global clinical measure of fitness and frailty in elderly people. CMAJ 173:489-495

31. Searle SD, Mitnitski A, Gahbauer EA, Gill TM, Rockwood K (2008) A standard procedure for creating a frailty index. BMC Geriatr 8:24

32. Jones D, Song X, Mitnitski A, Rockwood K (2005) Evaluation of a frailty index based on a comprehensive geriatric assessment in a population based study of elderly Canadians. Aging Clin Exp Res 17:465-471

33. Fried LP, Tangen CM, Walston J, Newman AB, Hirsch C, Gottdiener $J$ et al (2001) Frailty in older adults evidence for a phenotype. J Gerontol A Biol Sci Med Sci 56:M146-M157

34. Morley JE, Malmstrom TK, Miller DK (2012) A simple frailty questionnaire (FRAIL) predicts outcomes in middle-aged African Americans. J Nutr Health Aging 16:601-608

35. Rolfson DB, Majumdar SR, Tsuyuki RT, Tahir A, Rockwood K (2006) Validity and reliability of the Edmonton Frail Scale. Age Ageing 35:526-529

36. Akgün KM, Tate JP, Crothers K, Crystal S, Leaf DA, Womack J et al (2014) An adapted frailty-related phenotype and the VACS index as predictors of hospitalization and mortality in HIVinfected and uninfected individuals. JAIDS J Acquir Immune Defic Syndr 67:397-404

37. Clegg A, Bates C, Young J, Ryan R, Nichols L, Teale EA et al (2016) Development and validation of an electronic frailty index using routine primary care electronic health record data. Age Ageing 45:353-360

38. Theou O, Cann L, Blodgett J, Wallace LM, Brothers TD, Rockwood K (2015) Modifications to the frailty phenotype criteria: systematic review of the current literature and investigation of 262 frailty phenotypes in the Survey of Health, Ageing, and Retirement in Europe. Ageing Res Rev 21:78-94. https://doi. org/10.1016/j.arr.2015.04.001

39. Salem BE, Nyamathi A, Phillips LR, Mentes JC, Sarkisian C, Brecht M-L (2014) Development of a frailty framework among vulnerable populations. Adv Nurs Sci 37:70-81

40. Guaraldi G, Malagoli A, Theou O, Brothers TD, Wallace LM, Torelli R et al (2017) Correlates of frailty phenotype and frailty index with clinical outcomes in people aging with HIV. HIV Med 18(10):764-771. https://doi.org/10.1111/hiv.12527

41. Guaraldi G, Rockwood K (2017) Geriatric-HIV medicine is born. Clin Infect Dis 65:507-509

42. Cresswell FV, Levett $\mathrm{T}$ (2017) Specialist care of older adults with HIV infection in the UK: a service evaluation. HIV Med 18:519-524

43. Brothers TD, Kirkland S, Guaraldi G, Falutz J, Theou O, Johnston BL et al (2014) Frailty in people aging with human immunodeficiency virus (HIV) infection. J Infect Dis 210:1170-1179

44. Levett TJ, Cresswell FV, Malik MA, Fisher M, Wright J (2016) Systematic review of prevalence and predictors of frailty in individuals with human immunodeficiency virus. J Am Geriatr Soc 64:1006-1014

45. Veeravelli S, Najafi B, Marin I, Blumenkron F, Smith S, Klotz SA (2016) Exergaming in older people living with HIV improves balance, mobility and ameliorates some aspects of frailty. J Vis Exp 6(116):e54275-e54275. https://doi. org/10.3791/54275

46. Önen NF, Agbebi A, Shacham E, Stamm KE, Önen AR, Overton ET (2009) Frailty among HIV-infected persons in an urban outpatient care setting. J Infect 59:346-352

47. Guaraldi G, Zona S, Brothers TD, Carli F, Stentarelli C, Dolci $\mathrm{G}$ et al (2015) Aging with HIV vs. HIV seroconversion at older age: a diverse population with distinct comorbidity profiles. PLoS One 10(4):e0118531
48. Piggott DA, Muzaale AD, Mehta SH, Brown TT, Patel KV, Leng SX et al (2013) Frailty, HIV infection, and mortality in an aging cohort of injection drug users. PLoS One 8:e54910

49. Brothers TD, Kirkland S, Theou O, Zona S, Malagoli A, Wallace LMK et al (2017) Predictors of transitions in frailty severity and mortality among people aging with HIV. PLoS One 12:e0185352

50. Önen NF, Patel P, Baker J, Conley L, Brooks JT, Bush T et al (2014) Frailty and pre-frailty in a contemporary cohort of HIVinfected adults. J Frailty Aging 3:158-165

51. Brañas F, Jiménez Z, Sánchez-Conde M, Dronda F, De LópezBernaldo Quirós JC, Pérez-Elías MJ et al (2017) Frailty and physical function in older HIV-infected adults. Age Ageing 46:522-526

52. Althoff KN, Jacobson LP, Cranston RD, Detels R, Phair JP, Li $X$ et al (2014) Age, comorbidities, and AIDS predict a frailty phenotype in men who have sex with men. J Gerontol A Biol Sci Med Sci 69A:189-198

53. Erlandson KM, Ng DK, Jacobson LP, Margolick JB, Dobs AS, Palella FJ et al (2017) Inflammation, immune activation, immunosenescence, and hormonal biomarkers in the frailty-related phenotype of men with or at risk for HIV infection. J Infect Dis 215:228-237

54. Ianas V, Berg E, Mohler MJ, Wendel C, Klotz SA (2013) Antiretroviral therapy protects against frailty in HIV-1 infection. J Int Assoc Provid AIDS Care 12:62-66

55. Akgün KM, Tate JP, Oursler KK, Crystal S, Leaf DA, Womack JA et al (2016) Association of chronic obstructive pulmonary disease with frailty measurements in HIV-infected and uninfected veterans. AIDS 30:2185-2193

56. Petit N, Enel P, Ravaux I, Darque A, Baumstarck K, Bregigeon S et al (2018) Frail and pre-frail phenotype is associated with pain in older HIV-infected patients. Medicine (Baltimore). https://doi. org/10.1097/md.0000000000009852

57. Hawkins KL, Zhang L, Ng DK, Althoff KN, Palella FJ, Kingsley LA et al (2018) Abdominal obesity, sarcopenia, and osteoporosis are associated with frailty in men living with and without HIV. AIDS 32:1257-1266

58. Bregigeon S, Galinier A, Zaegel-Faucher O, Cano CE, Obry V, Laroche $\mathrm{H}$ et al (2017) Frailty in HIV infected people: a new risk factor for bone mineral density loss. AIDS 31(11):1573-1577

59. Guaraldi G, Brothers TD, Zona S, Stentarelli C, Carli F, Malagoli A et al (2015) A frailty index predicts survival and incident multimorbidity independent of markers of HIV disease severity. AIDS 29:1633-1641

60. Franconi I, Theou O, Wallace L, Malagoli A, Mussini C, Rockwood K et al (2018) Construct validation of a frailty index, an HIV index and a protective index from a clinical HIV database. PLoS One 13:e201394

61. Marquine MJ, Montoya JL, Umlauf A, Fazeli PL, Gouaux B, Heaton RK et al (2016) The Veterans Aging Cohort Study (VACS) Index and neurocognitive change: a longitudinal study. Clin Infect Dis 63:694-702

62. Piggott DA, Muzaale AD, Varadhan R, Mehta SH, Westergaard RP, Brown TT et al (2017) Frailty and cause-specific hospitalization among persons aging with HIV infection and injection drug use. J Gerontol A Biol Sci Med Sci 72:389-394

63. Womack JA, Goulet JL, Gibert C, Brandt CA, Skanderson M, Gulanski B et al (2013) Physiologic frailty and fragility fracture in HIV-infected male veterans. Clin Infect Dis 56:1498-1504

64. Justice AC, Tate JP, Freiberg MS, Rodriguez-Barradas MC, Tracy $R$ et al (2012) Reply to Chow et al. Clin Infect Dis 55:751-752

65. Guaraldi G, Dolci G, Zona S, Tarantino G, Serra V, Ballarin R et al (2017) A frailty index predicts post-liver transplant morbidity and mortality in HIV-positive patients. AIDS Res Ther 14:37

66. Erlandson KM, Perez J, Abdo M, Robertson K, Ellis RJ, Koletar SL et al (2018) Frailty, neurocognitive impairment, or both in predicting poor health outcomes among adults living with HIV. 
Clin Infect Dis. https://doi.org/10.1093/cid/ciy430 (Epub ahead of print)

67. Wallace LMK, Ferrara M, Brothers TD, Garlassi S, Kirkland SA, Theou O et al (2017) Lower frailty is associated with successful cognitive aging among older adults with HIV. AIDS Res Hum Retroviruses 33:157-163

68. Ding Y, Lin H, Liu X, Wong FY, Sun YV, Marconi VC et al (2017) Higher prevalence of frailty among a sample of HIVinfected middle-aged and older Chinese adults is associated with neurocognitive impairment and depressive symptoms. J Infect Dis 215:687-692

69. Marquine MJ, Umlauf A, Rooney AS, Fazeli PL, Gouaux BD, Woods SP et al (2014) The Veterans Aging Cohort Study index is associated with concurrent risk for neurocognitive impairment. JAIDS J Acquir Immune Defic Syndr 65:190-197

70. Oppenheim H, Paolillo EW, Moore RC, Ellis RJ, Letendre SL, Jeste DV et al (2018) Neurocognitive functioning predicts frailty index in HIV. Neurology 91:e162-e170

71. Kooij KW, Wit FW, Schouten J, van der Valk M, Godfried MH, Stolte IG et al (2016) HIV infection is independently associated with frailty in middle-aged HIV type 1-infected individuals compared with similar but uninfected controls. AIDS 30(2):241-250

72. Sok P, Gardner S, Bekele T, Globerman J, Seeman MV, Greene $S$ et al (2018) Unmet basic needs negatively affect health-related quality of life in people aging with HIV: results from the Positive Spaces, Healthy Places study. BMC Public Health 18:644

73. Hessol NA, Zepf R, Zobell E, Weiser SD, John MD (2017) Food insecurity and aging outcomes in older adults living with HIV. AIDS Behav 21(12):3506-3514. https://doi.org/10.1007/s1046 1-017-1838-y

74. Bogart LM, Landrine H, Galvan FH, Wagner GJ, Klein DJ (2013) Perceived discrimination and physical health among HIV-positive black and latino men who have sex with men. AIDS Behav 17:1431-1441

75. Aidala AA, Wilson MG, Shubert V, Gogolishvili D, Globerman J, Rueda $S$ et al (2015) Housing status, medical care, and health outcomes among people living with HIV/AIDS: a systematic review. Am J Public Health 106:e1-e23

76. House JS, Lepkowski JM, Kinney AM, Mero RP, Kessler RC, Herzog AR (1994) The social stratification of aging and health. J Health Soc Behav 35:213-234

77. Rhodes T (2002) The, "risk environment": a framework for understanding and reducing drug-related harm. Int J Drug Policy 13:85-94
78. Enel P, Retornaz F, Ravaux I, de Jaureguiberry J-P, Philibert P, Allegre T, Chadapaud S, Cohen-Valensi R, Granet-Brunello P, Pelissier L, Pichancourt G, Bregigeon S, Tollinchi F, Darque A, Petit N (2018) Factors associated with social deprivation among older persons living with HIV. AIDS Care. https://doi. org/10.1080/09540121.2018.1549719

79. Rhodes T, Singer M, Bourgois P, Friedman SR, Strathdee SA (2005) The social structural production of HIV risk among injecting drug users. Soc Sci Med 61:1026-1044

80. Singh HK, Del Carmen T, Freeman R, Glesby MJ, Siegler EL (2017) From one syndrome to many: incorporating geriatric consultation into HIV care. Clin Infect Dis 65:501-506

81. Linee Guida Italiane sull'utilizzo dei farmaci antiretrovirali e sulla gestione diagnostico-clinica delle persone con infezione da HIV-1; 2016. http://www.salute.gov.it/imgs/C_17_pubblicazi oni_2545_allegato.pdf. Accessed 5 Dec 2018

82. Abrass CK, Appelbaum JS, Boyd CM, Braithwaite RS, Broudy VC, Covinsky K. Recommended treatment strategies for clinicians managing older patients with HIV. HIV aging consensus project. Available at: https://aahivm.org/wp-content/uploads/2017/02/ Aging-report-working-document-FINAL-12.1.pdf. Accessed 5 Dec 2018

83. Sangarlangkarn A, Appelbaum JS (2016) Caring for older adults with the human immunodeficiency virus. J Am Geriatr Soc 64(11):2322-2329. https://doi.org/10.1111/jgs.14584

84. Levett T, Wright J (2017) How to assess and manage frailty in patients with HIV. Sex Transm Infect 93(7):476-477. https://doi. org/10.1136/sextrans-2016-052663

85. Greene M, Justice AC, Lampiris HW, Valcour V (2013) Management of human immunodeficiency virus infection in advanced age. JAMA 309:1397-1405

86. Pilotto A, Cella A, Pilotto A, Daragjati J, Veronese N, Musacchio C et al (2017) Three decades of comprehensive geriatric assessment: evidence coming from different healthcare settings and specific clinical conditions. J Am Med Dir Assoc 18:192.e1-192.e11

87. Rockwood K, Howlett S, Stadnyk K, Carver D, Powell C, Stolee P (2003) Responsiveness of goal attainment scaling in a randomized controlled trial of comprehensive geriatric assessment. J Clin Epidemiol 56:736-743 